\title{
DROPSHIPPING DALAM PERSPEKTIF EKONOMI ISLAM
}

\author{
Oleh: \\ Irdlon Sahil ${ }^{1}$ \\ Email: irdlonsahil88@gmail.com
}

\begin{abstract}
This study was intended to explain the dropshipping in the Islamic perspektif.. This method of research is done by reading reference books, journals and other media related to dropshipping. This studies show that dropshipping is a product sale that allows the dropshipper to sell goods to customers by thinking about supplier's photos or the supplier's store without having to shovel and sell to customers at a price determined by the dropshipper. Doing Islamic trafficking has illustrated good and proper ordinances so that there's no harm among humans in making transactions. The legal basis for selling and selling is found in several verses in the Qur'an among them Qs. al-Baqarah:275, Qs. al-Baqarah: 282, Qs. an-Nisa': 24. Islam allows the dropshipping system to use akad salam, that would be the buying of the goods submitted later on, while the payment was made earlier.
\end{abstract}

Keywords: Dropshipping, Islam

\section{Pendahuluan}

Jual beli merupakan transaksi yang sering dilakukan oleh setiap orang. Dalam perkembangan teknologi yang ada, jual beli pada zaman dahulu berbeda dengan jual beli pada zaman modern ini. Sehingga, proses jual beli yang ada banyak hal yang harus diperhatikan supaya jual beli tersebut menjadi sah secara hukum ekonomi syari'ah. Jual beli dalam Islam pada umumnya menjelaskan adanya transaksi yang bersifat fisik atau pihak yang bertransaksi bertatap muka, dengan menghadirkan benda ketika terjadi akad atau tanpa menghadirkan benda yang dipesan. Dengan

${ }^{1}$ Dosen Prodi Pendidikan Bahasa Arab STAI Syaichona Moh. Cholil Bangkalan 
ketentuan harus dinyatakan sifat dan kriterianya sampai penyerahannya dalam tempo waktu yang telah ditentukan. ${ }^{2}$

Zaman modern kini telah banyak membawa perubahan dalam hal jual beli, seperti memanfaatkan media internet sehingga proses bertransaksi atau jual beli kian mudah dan cepat. Bagaimana menjual, mempromosikan, dan beradu harga hanya dengan komunikasi jarak jauh dengan waktu kapan pun di manapun dan dengan siapa pun. Tanpa harus mempertemukan pihak yang bertransaksi secara fisik, inilah yang disebut transaksi yang mudah dan cepat karena perkembangan teknologi. ${ }^{3}$

Kegiatan bisnis melalui media internet juga telah menggeser sistem bertransaksi jual beli masyarakat yang pada mulanya dengan cara offline ke sistem jual beli online. Pergeseran tersebut artinya sistem transaksi offline merupakan adanya perjumpaan langsung antara penjual dan pembeli dimana pihak pembeli dapat memilih secara langsung barang yang akan dibeli. Sistem offline telah banyak tergantikan dengan sistem online dimana antara penjual dan pembeli tidak diharuskan untuk bertatap muka. Jual beli atau perdagangan menggunakan media internet juga disebut dengan electronic commerce (e-commerce). ${ }^{4}$

Jual beli atau perdagangan menggunakan media internet yang disebut electronic commerce (e-commerce) kini sudah tidak asing lagi dalam dunia bisnis di negara-negara berkembang maupun maju termasuk di Indonesia. Seiring berjalannya waktu e-commerce pun menjadi lebih berkembang dalam hal model transaksi jual beli, salah satunya adalah model transaksi jual beli dropshipping.

Model transaksi dropshipping merupakan bagian dari jenis bisnis online afiliasi, maksudnya yaitu pelaku bisnis dropship memasarkan produk orang lain melalui fasilitas online di internet. Baik berupa barang maupun jasa, produk-produk tersebut bukan merupakan milik sendiri.

\footnotetext{
${ }^{2}$ Mardani, Fiqh Ekonomi Syariah. Jakarta: Kencana. 2011. hlm 120. Selanjutnya ditulis Mardani, Fiqh.

${ }^{3}$ Jusmaliani, Bisnis Berbasis Syari'ah. Jakarta: Bumi Aksara. 2008. hlm 198 dan 199. Selanjutnya ditulis Jusmaliani, Bisnis.

${ }^{4}$ Muflihatul Bariroh. Transaksi Jual Beli Dropshipping dalam Perspektif Fiqh Muamalah. Jurnal Ahkam Volume 4, Nomor 2, November 2016: 199-216
} 
Jual beli dengan sistem dropship ini mendapat banyak respon dari masyarakat, baik yang setuju maupun tidak setuju. Mereka mempunyai alasan tersendiri tentang boleh tidaknya sistem jual beli ini. Jual beli dengan sistem dropship diperbolehkan apabila dropshipper dalam melakukan jual beli ini sesuai dengan syarat jual beli yang telah ditentukan.

Namun jual beli dengan cara seperti dropship dimungkinkan mengandung unsur gharar (unsur ketidakpastian), disebabkan karena barang yang dijadikan objek jual beli bukan milik penuh penjual, sehingga pada saat akad berlangsung penjual belum dapat memastikan apakah barang tersebut dapat dikirimkan kepada pembeli atau tidak. Selain itu, karena barang tersebut dijual dalam bentuk gambar, maka terdapat pula ketidakpastian karakter ataupun kualitas produk yang belum tentu sama dengan gambar atau foto yang dipajang di toko online tersebut.

\section{Haikikat Dropshipping}

Dropship pada dasarnya merupakan jual beli yang dilakukan antara penjual dan pembeli dengan menggunakan media internet, dropshipping adalah penjualan produk yang memungkinkan dropshipper (reseller) menjual barang ke pelanggan dengan bermodalkan foto dari supplier atau toko (tanpa harus menyetok barang) dan menjual ke pelanggan dengan harga yang ditentukan oleh dropshipper.

Transaksi jual beli dropship adalah sebagai berikut: setelah pembeli menentukan barang yang dikehendaki kemudian pembeli mentransfer uang ke rekening dropshipper, dropshipper membayar kepada supplier sesuai dengan harga beli dropshipper (ditambah dengan ongkos kirim ke pembeli) serta memberikan data-data pelanggan (nama,alamat,nomor telepon) kepada supplier. Barang yang dipakai akan dikirim oleh supplier ke pembeli.

Contohnya adalah seperti ini: "Andi merupakan pengusaha garmen yang menjual busana muslimah, kemudian Andi memproduksi dan memfoto beberapa busana tersebut dan memasarkannya dengan cara bisnis online. Kemudian ada beberapa reseller Andi (penjual yang ingin bergabung memasarkan produk yang dibuat oleh Andi) mengambil fotofoto yang dipasarkan oleh Andi dan reseller tersebut memasarkan kepada 
konsumen (hanya dengan bantuan foto). Ketika konsumen membeli produk tersebut dari reseller Andi/dropshipper, maka reseller/dropshipper tersebut memerintahkan kepada konsumen untuk membayar dengan cara transfer, reseller/dropshipper itu pun membeli dari Andi dan Andi langsung mengirimkan barang yang dibeli oleh konsumen reseller/dropshipper tersebut. Dengan cara mencantumkan bahwa nama pengirim adalah nama reseller/dropshipper Andi". ${ }^{5}$

Banyak orang yang menggunakan sistem jual beli ini sebagai pekerjaan sampingan, karena proses dan cara kerjanya yang tidak merepotkan, bisa dilakukan dimana saja dan kapan saja tidak membutuhkan modal, waktu, dan tenaga yang besar, serta tidak membutuhkan gudang untuk menyimpan barang. Namun, transaksi dengan model ini mampu memicu menjamurnya perilaku dropshipping karena aktivitas ini relatif mudah dan bisa dilakukan oleh siapa saja yang ingin berjualan di kancah bisnis online tanpa mempersiapkan modal terlebih dahulu. Aktivitas ini, di satu sisi, menguntungkan banyak orang. Akan tetapi, di sisi lain, masih dipertanyakan keabsahannya secara syariat. Terlebih jika dropshipping dalam menjual produk lewat gambar itu tidak mengetahui secara detail produk yang akan dijual olehnya, sehingga konsumen seringkali dirugikan karena produk riil tidak sesuai dengan gambar dan bahkan lebih buruk dari gambar. ${ }^{6}$

\section{Landasan Hukum Dropshipping}

Dalam perihal jual beli, Islam mendorong agar manusia melakukan jual beli sebagai salah satu cara manusia dalam memenuhi kebutuhannya. Dengan melakukan jual beli maka manusia akan tercipta rasa tolong menolong, rasa kebersamaan, dan rasa membutuhkan satu sama lain.

Dalam melakukan jual beli pun Islam telah menggambarkan tata cara yang baik dan benar agar tidak ada kerugian di antara manusia-manusia

${ }^{5}$ Ika Yunia Fauzia, Akad Wakalah dan Samsarah Sebagai Solusi atas Klaim Keharaman Dropship dalam Jual Beli Online, ISLAMICA: Jurnal Studi Keislaman No. 2 Vol. 9 (Maret, 2015)

${ }^{6}$ Ibid. 
yang melakukan transaksi jual beli. Dasar hukum perihal jual beli terdapat dalam beberapa ayat di dalam Al-Qur'an, di antaranya:

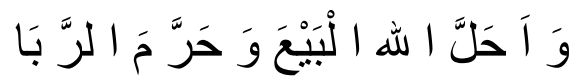

"Padahal Allah telah menghalalkan jual beli dan mengharamkan riba"(Surah al-Baqarah 2:275)

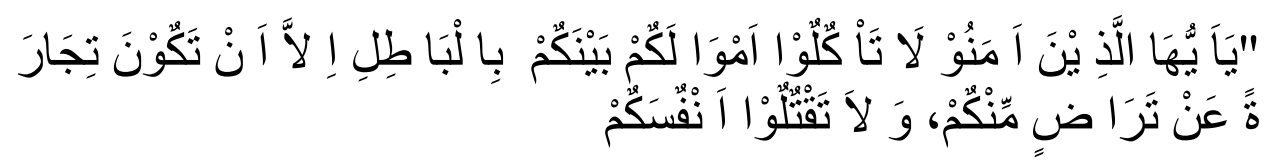

"Hai orang-orang yang beriman, janganlah kamu saling memakan harta sesamamu dengan jalan yang batil, kecuali dengan jalan perniagaan yang berlaku dengan suka sama suka diantara kamu, Dan janganlah kamu membunuh dirimu; sesungguhnya Allah adalah Maha Penyayang kepadamu" (Surah an-Nisa' 4:29) ${ }^{8}$.

Jual beli adalah merupakan suatu akad, dan dapat dikatakan sah apabila telah memenuhi rukun dan syarat jual beli. Akad ialah ikatan kata antara penjual dan pembeli. Jual beli belum dapat dikatakan sah apabila ijab dan qabul belum dilakukan, karena ijab qabul menunjukkan kerelaan (keridhaan) di antara kedua belah pihak. Rukun jual beli itu ada 4, yaitu sebagai berikut.

1. Orang yang berakad (penjual dan pembeli).

2. Sighat (lafaz ijab dan qabul).

3. Ada barang yang dibeli.

4. Ada nilai tukar pengganti barang.

Menurut Mazhab Hanafi, orang yang berakad, barang yang dibeli, dan nilai tukar barang di atas, termasuk syarat jual beli bukan rukun. Dalam bertransaksi itu diperlukan rukun-rukun. Adapun rukun jual beli ada tiga, yaitu akad (ijab qabul), orang yang berakad (penjual dan pembeli), dan

${ }^{7}$ Al-Qur'an Terjemahnya Special for Women. Departemen Agama RI ${ }^{8}$ Ibid. 
ma'kud alaih (objek akad)9. Sedangkan mayoritas ulama, menetapkan bahwa syarat jual beli sesuai dengan rukun jual belinya, yakni ${ }^{10}$ :

1. Syarat orang yang berakad:

a. Berakal dan mumayyiz; tidak sah jual beli yang dilakukan oleh orang gila, anak kecil, dan orang bodoh.

b. Berjumlah dua orang atau lebih.

2. Syarat ma'qud 'alaih (harga atas nilai tukar pengganti barang dan barang yang dibeli)

a. Barang yang dijual diketahui dengan jelas.

b. Barang yang dijual merupakan benda yang bernilai atau bermanfaat.

c. Barang yang dijual merupakan hak milik penjual.

d. Barang yang dijual dapat diserahterimakan.

3. Syarat Sighat (lafadz ijab dan qabul)

a. Kecakapan; kedua belah pihak haruslah orang yang cakap dalam melakukan transaksi.

b. Adanya kesesuaian antara ijab dan qabul.

c. Dilakukan dalam satu tempat.

\section{Persamaan Dropship dan Salam}

Dropship dapat dikatakan halal jika sistem jual belinya memakai akad salam (bai' as-salam). Salam atau yang juga disebut sebagai salaf berarti pembelian barang yang diserahkan di kemudian hari, sedangkan pembayaran dilakukan di awal. Sistem dropship memiliki kesamaan dengan sistem salam paralel. Di samping segenap rukun harus terpenuhi, bai' assalam juga mengharuskan tercukupinya segenap syarat pada masingmasing rukun. Di bawah ini akan diuraikan dua di antara rukun-rukun terpenting, yaitu modal dan barang.

${ }^{9}$ Sohari Sahrani dan Ru'fah Abdullah, Fiqh Muamalat. Cet.1. Bogor: Penerbit Ghalia Indonesia, 2011. hlm 67.

${ }^{10}$ Isnawati Rais dan Hasanudin. Fiqh Muamalat dan Aplikasinya Pada LKS. Jakarta: Lembaga Penelitian UIN Syarif Hidayatullah. 2011 hlm 69. 
1. Modal Transaksi Bai' as-Salam

Syarat-syarat yang harus di penuhi dalam modal bai' as-salam adalah sebagai berikut: pertama modal harus diketahui, yakni barang yang akan disuplai harus diketahui jenis, kualitas, dan jumlahnya. Hukum awal mengenai pembayaran adalah bahwa ia harus dalam bentuk uang tunai.

Kedua, penerimaan pembayaran salam, kebanyakan ulama mengharuskan pembayaran salam dilakukan ditempat kontrak. Hal tersebut dimaksudkan agar pembayaran yang diberikan oleh al-muslam (pembeli) tidak dijadikan sebagai utang penjual ${ }^{11}$.

2. Al-Muslam Fiihi (barang)

Syarat-syarat yang harus dipenuhi dalam al-muslam, sebagai berikut .

a. Harus spesifik dan dapat diakui sebagai utang

b. Penyerahan barang dilakukan di kemudian hari

c. Bolehnya menentukan tanggal waktu di masa yang akan datang untuk penyerahan barang

d. Tempat penyerahan

e. Penggantian muslam fiihi dengan barang lain. ${ }^{12}$

Dalam al-Qur'an:

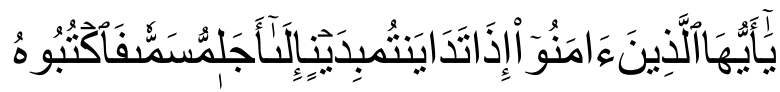

"Hai orang-orang beriman, apabila kamu bermuamalah tidak secara tunai untuk waktu yang ditentukan, hendaklah kamu menuliskannya.." (al-Baqarah : 282)

Dalam hadist

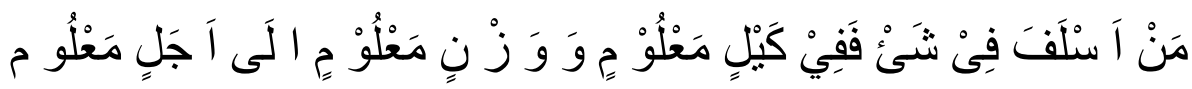

"Barangsiapa yang melakukan salaf (salam), hendaknya ia melakukan dengan takaran yang jelas dan timbangan yang jelas pula, untuk jangka waktu yang diketahui."(HR Ibnu Abbas) $)^{13}$

\footnotetext{
${ }^{11}$ Dr. Muhammad Syafii Antonio. Jakarta: Gema Insani. 2001, hlm 109.

${ }^{12}$ Dr. Muhammad Syafii Antonio. Jakarta: Gema Insani. 2001, hlm 110.
} 
Dari akad di atas maka jual beli dropship ini tidak melanggar ketentuan syariah. Meski kita sebagai penjual belum punya barangnya, dan modal kita cuma speak saja, tetapi syariat Islam membolehkan akad seperti ini. Akadnya yang di pakai, yaitu akad salam. Pembeli membayar dulu kepada kita atas suatu barang atau jasa yang belum kita serahkan, bahkan belum kita miliki. Lalu uang pembayarannya itu baru kita belikan barang yang dimaksud, dan kita jualkan kepada si pembeli, dimana kita mendapatkan selisih harganya.

Kalau barang itu mau diatas-namakan milik kita juga boleh, karena memang benar-benar membeli dari sumbernya dan kita menjual kembali. Bahwa barang itu tidak sempat mampir ke tangan kita, tidak menjadi masalah ${ }^{14}$.

\section{Penutup}

Dropshipping adalah penjualan produk yang memungkinkan dropshipper (reseller) menjual barang ke pelanggan dengan bermodalkan foto dari supplier atau toko (tanpa harus menyetok barang) dan menjual ke pelanggan dengan harga yang ditentukan oleh dropshipper.

Dalam melakukan jual beli Islam telah menggambarkan tata cara yang baik dan benar agar tidak ada kerugian di antara manusia yang melakukan transaksi jual beli. Dasar hukum perihal jual beli terdapat dalam beberapa ayat di dalam al-Qur'an, antara lain: Qs. al-Baqarah: 275, Qs. al-Baqarah: 282, Qs. an-Nisa: 24. Islam memperbolehkan sistem droshipping dengan cara menggunakan akad salam, berarti pembelian barang yang diserahkan di kemudian hari, sedangkan pembayaran dilakukan di awal.

\footnotetext{
${ }^{13}$ Dr. Muhammad Syafii Antonio. Jakarta: Gema Insani. 2001, hlm 108.

${ }^{14}$ http://www.slideshare.net//halalkah-dropship, diakses tanggal 18 Oktober 2018
} 


\section{DAFTAR PUSTAKA}

Al-Qur'an Terjemahnya Special for Women. Departemen Agama RI

Antonio, Muhammad Syafii. 2001. Jakarta: Gema Insani.

Bariroh, Muflihatul. 2016. Transaksi Jual Beli Dropshipping dalam Perspektif Fiqh Muamalah. Jurnal Ahkam, Volume 4. Nomor 2, November 2016: 199-216

Fauzia, Ika Yunia. 2015. Akad Wakalah dan Samsarah Sebagai Solusi atas Klaim Keharaman Dropship dalam Jual Beli Online. Jurnal Islamica: Jurnal Studi Keislaman No. 2 Vol. 9 (Maret, 2015)

http://www.slideshare.net//halalkah-dropship.

Jusmaliani. 2008. Bisnis Berbasis Syari'ah. Jakarta: Bumi Aksara.

Mardani. 2011. Fiqh Ekonomi Syariah. Jakarta: Kencana.

Rais, Isnawati dan Hasanudin. 2011. Figh Muamalat dan Aplikasinya Pada LKS. Jakarta: Lembaga Penelitian UIN Syarif Hidayatullah.

Sahrani, Sohari dan Ru'fah Abdullah. 2011. Figh Muamalat, Cet.1, Bogor: Ghalia Indonesia. 